\title{
Consumer and Food Product Determinants of Food Wasting: A Case Study on Chicken Meat
}

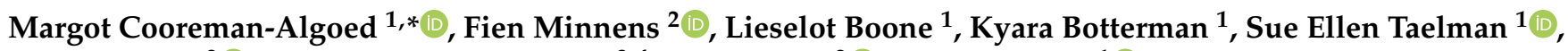 \\ Wim Verbeke ${ }^{2} \mathbb{( 1 )}$, Brecht Devleesschauwer ${ }^{3,4}$, Yung Hung ${ }^{2}{ }^{(1)}$ and Jo Dewulf ${ }^{1}(\mathbb{C}$ \\ 1 Research Group Sustainable Systems Engineering (STEN), Department of Green Chemistry and Technology, \\ Faculty of Bioscience Engineering, Ghent University, B-9000 Ghent, Belgium; lieselot.boone@ugent.be (L.B.); \\ kyara.botterman@ugent.be (K.B.); sueellen.taelman@ugent.be (S.E.T.); jo.dewulf@ugent.be (J.D.) \\ 2 Department of Agricultural Economics, Faculty of Bioscience Engineering, Ghent University, \\ B-9000 Ghent, Belgium; fien.minnens@ugent.be (F.M.); wim.verbeke@ugent.be (W.V.); \\ yung.hung@ugent.be (Y.H.) \\ 3 Department of Epidemiology and Public Health, Research Institute Sciensano, B-1050 Brussels, Belgium; \\ brecht.devleesschauwer@sciensano.be \\ 4 Department of Veterinary Public Health and Food Safety, Faculty of Veterinary Medicine, Ghent University, \\ B-9820 Merelbeke, Belgium \\ * Correspondence: margot.cooreman@ugent.be
}

Citation: Cooreman-Algoed, M.; Minnens, F.; Boone, L.; Botterman, K.; Taelman, S.E.; Verbeke, W.; Devleesschauwer, B.; Hung, Y.; Dewulf, J. Consumer and Food Product Determinants of Food Wasting: A Case Study on Chicken Meat. Sustainability 2021, 13, 7027. https://doi.org/10.3390/ su13137027

Academic Editors: Gaetano Chinnici and Giuseppe Antonio Di Vita

Received: 10 May 2021

Accepted: 16 June 2021

Published: 23 June 2021

Publisher's Note: MDPI stays neutral with regard to jurisdictional claims in published maps and institutional affiliations.

Copyright: (c) 2021 by the authors. Licensee MDPI, Basel, Switzerland. This article is an open access article distributed under the terms and conditions of the Creative Commons Attribution (CC BY) license (https:// creativecommons.org/licenses/by/ $4.0 /)$.

\begin{abstract}
Food wastage is an environmental concern worldwide, particularly regarding households. This study aims to identify household food wasting segments and to assess the relationship between both consumer and food product determinants and the identified segments. Data were collected through a consumer survey of several packaged chicken products $(n=256 ; 2019)$ in a retail setting in Belgium. Of the participants, 36\% reported never wasting any chicken meat. The average waste percentages were small, 1.1-3.1\%, depending on the packaged product, although they were not significantly different between products. Participants with low levels of self-reported chicken waste were significantly older, without children and/or unemployed. Moreover, their households scored better for household routines and skills. They also agreed more to intend not to waste food, experienced a stronger injunctive norm and perceived consumer effectiveness. Additionally, lower chicken product wastage was discovered for households purchasing organic products and products with both a lower food convenience grade and shorter shelf life. Some relationships between household wastage and food product determinants contrast with expectations based on literature. The cause can be that some determinants are more related to food wasting (e.g., when participants buy organic products) than others (e.g., the products' shelf life).
\end{abstract}

Keywords: food waste; consumer behaviour; chicken meat; packaging; poultry; sustainability

\section{Introduction}

According to the Food and Agricultural Organization (FAO) of the United Nations (UN), around one-third of food intended for human consumption is lost or wasted worldwide each year [1]. Many studies have highlighted the fact that households are responsible for high amounts of food waste in industrialised countries [1-3]. The environmental impact of food consumption, including its waste along the supply chain, often assessed through life cycle assessment (LCA), is substantial. Food consumption accounts for $30 \%$ of a European citizen's overall resource consumption [4]. Food loss and waste (FLW) along the complete supply chain contribute to $28 \%$ of the overall carbon footprint of the average U.S. diet [5]. Additionally, 51\% of the total climate impact of FLW can be attributed to households [2]. This impact, caused by households, results from burden accumulation through the life cycle of food. To reduce global food loss and waste and improve the three pillars of sustainability, target 12.3 was introduced within the Sustainability Development Goals (SDG) of the UN. The aim is to "halving per capita global food waste at retail and 
consumer levels and reducing food loss along the production supply chains, including post-harvest losses, by 2030" [6].

To get a clear understanding of what food loss and/or waste comprehends, several definitions have been introduced [7,8]. Most definitions consider the quantitative aspect of FLW, while others also focus on loss in quality-for example, nutritional, food safety, and cosmetic degradation [7,9]. Some even include food overconsumption as a form of FLW [7]. The FAO introduced a conceptual framework that is generally applicable to define FLW. They describe it as "the decrease in quantity or quality of food along the food supply chain". Within this definition, food loss refers to food discarded at the beginning of the supply chain up to, but excluding, the retail phase. Food waste takes place at the retail and/or consumption level. Food is described as what is intended for human consumption-thus leaving out inedible parts, such as bones in meat or fish. Not all food lost in the supply chain is considered to be FLW. Only when it has no economically productive use (e.g., for the production of biodiesel or bioplastics) but is sent to waste treatment is it accounted for as FLW [7]. In this study, the above definition is applied [7].

To comprehend why food waste occurs, a theoretical model on the causes and determinants of consumers' food waste was introduced by the authors of [10]. This model specifies that motivations to avoid food waste result in more food waste prevention (FWP) household practices. However, these motivations only lead to these practices when consumers have the abilities and opportunities to reduce food waste. These abilities include having the skills to accurately plan how much food is needed in the household or the capability to cook creatively. Opportunities comprise, for example, the availability and accessibility of products and available storage equipment. Furthermore, competing goals can influence FWP household practices negatively. For example, food may be sacrificed (i.e., wasted) in order to reach these competing goals-such as preventing disliked tastes of dishes. Additionally, multiple sociodemographic characteristics have been associated with the generated amount of household food waste. The model hypothesises that these characteristics influence the consumer's motivation, abilities and opportunities. The insight that household food waste is not the consequence of one single behaviour has been confirmed by additional studies [11-14].

Besides consumer determinants, food product determinants, such as packaging characteristics, have been reported to have a great potential to support food waste reduction [15]. The review of [16] identified three clusters of packaging functions (i.e., specific roles of a package): protection, facilitating handling, and communication. Within these functions, features were defined as package characteristics that are required to fulfill a function. The first function is to protect the content of the package at every stage of the food supply chain. Features within this function are mechanical, barrier, thermal, and sealing properties. Facilitating handling can be accomplished by the physical design of the package. Features such as weight, unitisation, apportionment, fill rate, openability, and ease of emptying offer conveniences to actors along the supply chain, including consumers. Communication with consumers and other actors in the supply chain involves features that provide instructions about the product and its packaging [16].

Most food products-including meat, cheese and vegetables—are sold as packaged products in high-income regions [17]. The share of chicken on the total meat production has tripled in the last decades [18], making it a prominent food source. Animal products-including chicken meat-have a higher greenhouse gas impact compared to most plant-based products [19]. In addition to the food product impact, its FLW is responsible for an increased burden, especially when it takes place at the end of the supply chain-i.e., by consumers [2]. Eliminating chicken meat wastage at households might be challenging, as the perishable nature of chicken makes safe storage difficult [20]. Cases of common foodborne disease, such as campylobacteriosis, are most frequently linked to the consumption of contaminated poultry [21,22]. To ensure microbial safety, cold storage and suitable packaging are essential [23]. 


\section{Literature Review}

\subsection{Consumer Determinants Resulting in Household Food Waste}

Types of consumer determinants that might affect food waste generation and that have been studied previously are discussed in the following sections.

\subsubsection{Sociodemographic Characteristics}

A lower degree of self-reported food wasting at home was associated with older consumers, fewer household members and a lower income [11]. Contrary to this observation, [10] only indicated an influence of age and household size on household food waste, while no significant correlation was found for income, gender, household composition and education.

\subsubsection{Household Routines and Skills}

Shopping and reuse of leftovers routines were reported as the main drivers of food waste prevention, while planning routines only contributed rather indirectly. No significant association was established between household skills and shopping routines, although these skills did make an indirect contribution through planning routines [11]. Bravi [24] also reported that reusing leftovers aids in preventing and reducing food waste. Additionally, unplanned food purchases typically made consumer buy a lot of products and raise the level of food waste [24]. The authors of [10] highlighted similar conclusions: consumers who have accurate planning skills, who can cook creatively with leftovers and who know better how to prolong the shelf life of products waste less food.

\subsubsection{Motivations and Attitudes}

Stancu [11] reported that intentions not to waste food have a significant, although weak, effect on food waste amounts. However, the authors of [12] showed that having this intention does not affect reported food waste quantities. In addition to that, intentions not to waste are determined by injunctive norms (i.e., the belief that one should not burden the environment with food waste). This sensitivity to injunctive norms implies that the more consumers believe that they should not waste food, the stronger their goal is not to waste food [11].

\subsection{Consumer Classifications Based on Their Behaviour}

The determinants mentioned in Section 2.1. were assessed for the amount of household food waste generated but not for various consumer groups. The subsequent studies made efforts to define consumer groups or segments by applying a cluster analysis to classify the study participants. Firstly, the authors of [25] divided the participants into three groups based on their awareness of food waste, their wastefulness and their willingness to change their behaviour. Secondly, how well the participants were informed of FWP methods and how much they tried to reduce food waste was the base to define four participant groups [26]. Thirdly, Gaiani [27] introduced seven waster groups, providing a picture of food waste related to eating, shopping and storage behaviours; this study also unveiled several differences in the perceived quantities and causes of generated food waste. Moreover, research has been performed in a broader context, such as on the stated environmentally-friendly behaviour in the food domain [28] and the effects of diet change on reducing water consumption [29].

\subsection{Food Product Determinants Resulting in Household Food Waste}

Besides consumer determinants, food product determinants can also lead to differences in household food waste amounts and are discussed in the following sections.

\subsubsection{Packaging Size}

Inadequate packaging sizes have been reported to play a crucial role in food waste generation. The potential FLW amount may depend on the packaging function 'appor- 
tionment'. For example, a product can be offered in two packs of $75 \mathrm{~g}$ that can be opened separately instead of in one single $150 \mathrm{~g}$ pack. This smaller pack contains relatively more packaging, although it will normally result in a higher chance of consuming the food in time or less household food waste [30-32]. One-third of the households, in particular, claimed that they would produce less food waste if the size of the food packaging better met their needs [33]. Furthermore, $20-25 \%$ of household food waste was possibly caused by oversized packages and difficulties in emptying packages [15].

\subsubsection{Shelf Life}

Packaging technology has the potential to prolong a product's shelf life. For example, modified atmosphere packaging contains a modified gas composition that aims at reducing microbial growth and chemical deterioration of the food product [34]. Extending the shelf life- even by only a couple of days-for food, including meat products, can decrease food waste in households [35]. There is, however, no direct relationship between a longer shelf life and FLW generation [36].

\subsubsection{Agricultural Production Systems}

Besides packaging characteristics, some food product characteristics might lower food waste levels as well. Nevertheless, there has been no report of an association between eating organic foods and decreasing amounts of food waste [37], and therefore, requires additional research.

\subsubsection{Product Convenience Grade}

The product convenience grade of food products can range from zero (non-convenience food) to five (ready-to-serve foods that can be consumed after packaging removal/opening) [31]. For example, non-convenience foods are original raw foods, such as raw, not-precut vegetables or meat that still contains bones. Ready-to-serve foods are, for example, readyto-eat salads and desserts. Recently, both households and the food service sector have been increasingly using foods with a higher convenience grade to lessen the kitchen workload [31]. These foods are reported to be a potential measure to lower household food waste [38].

\subsection{Quantification of Household Food Waste}

In studies investigating both sets of determinants (Sections 2.1 and 2.3), the amount of household food waste is quantified using several methods. Objective measures rely on physical waste surveys, and subjective self-assessments are based on diaries or questionnaires. Self-assessment methods are more popular than objective measurements because of the lower cost, in some cases [39,40]. Additionally, they create the opportunity to obtain data, e.g., on sociodemographic characteristics of study participants and food waste causes [40]. Nevertheless, self-assessment methods are shown to underestimate measured food waste levels-14\% compared to physical waste surveys and $16 \%$ compared to food expenditure surveys $[39,41]$. A fair comparison amongst various studies with different methods might be difficult [39].

In conclusion, research that focuses on both consumer and food product determinants to assess the quantities of household food waste is, to our knowledge, lacking. No studies were found investigating the relationship between the two sets of determinants and consumer groups based on their amount of household food waste. Moreover, studies on consumer determinants related to household food waste chiefly assessed foods in general or food categories-thus, no specific food products $[10,11,24]$. To our knowledge, only one study examined these determinants for a specific food product, namely bread [42]. Little is known about food products with a high environmental impact and that are prone to food safety risks, such as those associated with chicken meat. That is the reason why this study aimed at assessing household food wastage due to both consumer and food product 
determinants. Data were collected through a consumer survey in a retail environment in Flanders, Belgium.

- Firstly, a thorough understanding was needed of the difference in consumer actions regarding chicken meat amongst the stages of purchasing, storage, preparation, and disposal. These consumers' actions are presented as the flow analysis, explaining where, how much and why food waste occurs.

- Participants were divided into segments according to the amount of chicken meat they generally waste, so-called household waster segments (HWS).

- Next, whether or not a relationship exists between both consumer and food product determinants and various HWS are analysed.

\section{Materials and Methods}

\subsection{Study Set-Up}

In this study, a questionnaire on five packaged chicken products sold at Colruyt and Bio-Planet retailers that are located, i.a. (inter alia) in Belgium, was developed. The observed chicken products, including their food product characteristics, are presented in Table 1. The chicken products consisted of diced chicken breast $0.5 \mathrm{~kg}$, chicken breasts $1 \mathrm{~kg}$, chicken breasts $0.5 \mathrm{~kg}$, chicken escalope $0.4 \mathrm{~kg}$ and organic whole chicken $1.5 \mathrm{~kg}$. The Colruyt Group retailer-including Colruyt and Bio-Planet-had a market share of $32.2 \%$ of all supermarkets in Belgium in 2019 [43]. The survey was conducted between 12 September and 30 October 2019 in 12 Colruyt and 3 Bio-Planet supermarkets, located in various provinces of Flanders, Belgium.

Data were collected through an in-person, computer-assisted personal interviewing (CAPI) consumer survey developed in the Qualtrics software. Each shopper who intended to buy meat products was invited to participate in the survey. The interviewer briefly explained the questions to the participants to limit possible misinterpretation and to ensure that all questions were answered. In total, 279 participants completed the questionnaire and some were excluded from the study (see Section 3.4), resulting in a final valid dataset of 256 cases.

\subsection{Questionnaire}

The questionnaire consisted of four parts and is described below (see also Supplementary Section S1). The four parts were as follows:

- Part 1: Identification of a commonly purchased chicken product.

- Part 2: Analysis of actions taken after the last routine purchase of a specific chicken product.

- Part 3: Quantification of self-reported food waste.

- Part 4: Influence of consumer determinants of household food waste.

The survey, excluding Part 2, consisted of 40 questions. The number of questions in Part 2 depended on the answers of the participants. The survey started with questions on the participant's actual behaviour (Part 1 and Part 2) in order to minimise social desirability bias. After these parts, questions regarding household routines and skills next to motivations and attitudes were randomised to reduce particular bias.

The survey length and interview duration were kept to a minimum because the retailer requested a time constraint of $15 \mathrm{~min}$ per participant and no incentive was provided. To cover a wide spectrum of relevant concepts, only one item from each of the validated constructs was selected and included in the present survey.

In the first part of the questionnaire, participants were interrogated to identify a chicken product that they frequently purchase at Colruyt or Bio-Planet retail stores (Table 1) and to report its purchasing frequency. 
Table 1. The chicken products including their food product characteristics.

\begin{tabular}{|c|c|c|c|c|c|}
\hline & $\begin{array}{c}\text { Diced Chicken Breast } \\
0.5 \mathrm{~kg}\end{array}$ & $\begin{array}{c}\text { Chicken Breasts } \\
1 \mathrm{~kg}\end{array}$ & $\begin{array}{c}\text { Chicken Breasts } \\
0.5 \mathrm{~kg}\end{array}$ & $\begin{array}{c}\text { Chicken Escalope } \\
0.4 \mathrm{~kg}\end{array}$ & $\begin{array}{c}\text { Organic Whole Chicken } \\
1.5 \mathrm{~kg}\end{array}$ \\
\hline \multicolumn{6}{|l|}{ Main packaging } \\
\hline Type & Container & Container & Container & Container & Duplex paper \\
\hline Mass (g) & 15.1 & 22.2 & $13.4^{1}$ & 11.9 & 12.7 \\
\hline \multicolumn{6}{|l|}{ Additional bag } \\
\hline Type & - & - & - & - & Compostable bag \\
\hline Material & - & - & - & - & Mater-Bi HF05S2 \\
\hline \multicolumn{6}{|l|}{ Lid } \\
\hline Material & PP & PP & PVC & PP & - \\
\hline Mass (g) & 1.8 & 2.1 & 0.8 & 1.8 & - \\
\hline \multicolumn{6}{|l|}{ Soak pad } \\
\hline Material & $61.9 \%$ Pulp and $38.1 \%$ fil & $61.9 \%$ Pulp and $38.1 \%$ film & PS & $61.9 \%$ Pulp and $38.1 \%$ film & - \\
\hline Mass (g) & 2.8 & 1.7 & $13.4^{1}$ & 2.8 & - \\
\hline \multicolumn{6}{|l|}{ Labels } \\
\hline Material & Paper & Paper & Paper & Paper & - \\
\hline Mass (g) & 3.3 & 1.3 & 0.3 & 3.3 & - \\
\hline Storage location & Fridge & Fridge & Fridge & Fridge & Fridge \\
\hline Packaging size ${ }^{3}$ & Small & Medium & Small & Small & Large \\
\hline Shelf life ${ }^{4}$ & Long & Long & Limited & Long & Limited \\
\hline Food convenience grade 5 & Ready-to-cook foods (2) & $\begin{array}{l}\text { Kitchen-ready food, inedible } \\
\text { parts have been removed (1) }\end{array}$ & $\begin{array}{l}\text { Kitchen-ready food, inedible } \\
\text { parts have been removed (1) }\end{array}$ & Ready-to-cook foods (2) & Non-convenience food (0) \\
\hline $\begin{array}{c}\text { Agricultural production } \\
\text { system }\end{array}$ & Conventional & Conventional & Conventional & Conventional & Organic \\
\hline
\end{tabular}

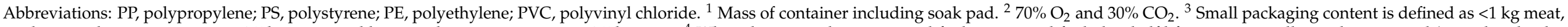

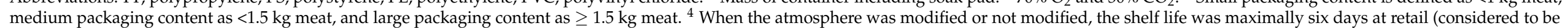
'long') and maximally four days at retail (considered to be 'limited'), respectively. ${ }^{5}$ Based on food convenience grades from [31]. 
In the second part, questions were asked about the last routine purchase of the chosen chicken product. Questions were included to understand how the product was handled at home. The focus was on storage (place and duration), preparation, consumption and wastage related to the packed product and its leftovers. Participants were asked if they had 'thrown away' the meat or whether it was 'fed to their pet'. Motivations for eventual wasting — based on [15] —were additionally questioned (e.g., 'bought too much' and 'packaging was too big or too small').

In Part 3, the self-reported chicken waste percentage of the chosen chicken product was assessed. Participants were asked the probability that a share of the packaging content was not consumed, or waste prevalence. In the case that some of the chicken meat became waste, the portion of the discarded package content was questioned (chicken waste percentage).

The questions in Part 4 dealt with food waste in general to analyse which consumer determinants are related to the amount of household chicken wasted. In particular, questions were developed to get an insight into the effect of sociodemographic characteristics on food waste-namely gender, age, household composition, number of children under the age of twelve, educational level, employment status and financial status. Participants were asked to assess their household routines and skills. For example, the extent to which FWP household practices were applied was investigated by using statements on the consumers' routines regarding planning, shopping, and reusing leftovers. Lastly, participants rated their motivations and attitudes towards food waste generation-e.g., motivation to avoid food waste focuses on the intention not to throw away food, the injunctive norm, and perceived behavioural control. A 5-point Likert interval scale was used to assess both household routines and skills and motivations and attitudes. Some questions were based on [11]; see Supplementary Section S1.4. The order of questions on household routines and skills next to those on motivations and attitudes were systematically varied to avoid affecting the participants' answers.

\subsection{Flow Analysis of Household Actions}

Based on Part 2 of the survey, a flow analysis was carried out to represent the share of participants that performed specific actions, from purchase to consumption and/or disposal of chicken meat. Equal weight was attributed when multiple actions occurred. For example, when a consumer indicated that chicken meat was 'partially consumed and partially stored', the action counted for 50\% as 'consumption' and for $50 \%$ as 'storage', independent of the mass share that was consumed and stored. This flow analysis was visualised applying e!sankey version 5.0 [44].

\subsection{Statistical Analysis}

Before statistically analysing the survey results, some of the cases were excluded from the study for several reasons. Firstly, eighteen cases related to products that were selected by a small number of participants were removed. These products were chicken drumsticks $1 \mathrm{~kg}(n=10)$ and organic chicken breasts $1 \mathrm{~kg}(n=8)$, which are, therefore, not presented in Table 1. Secondly, five additional cases were excluded because of inconsistencies in responses about chicken meat waste in general (Part 3) and chicken meat waste regarding the last routine purchase (Part 2) and answering an essential question with 'unsure'. Essential questions were questions that related to the estimation of the self-reported chicken waste (Section 3.2) or related to Part 2. After exclusion of these cases $(n=23)$, a valid dataset of 256 cases was obtained.

Next, the self-reported chicken waste percentage of the chosen chicken product was estimated. The calculation of this percentage was based on multiplying the waste prevalence (\%) with the chicken waste percentage (\%) (Section 3.2).

Cross tabulation analyses and Pearson's chi-square tests (for categorical variables) were next to the non-parametric Kruskal-Wallis test (for example, Likert-scale variables and continuous variables) performed on the final dataset. Significance values of Kruskal-Wallis 
were adjusted by the Bonferroni correction for multiple tests. Statistical significance was considered at the significance level of 0.05 . SPSS version 26 was used to examine the data.

\section{Results and Discussion}

\subsection{Understanding the Household Activities and Their Relation to Food Wasting}

The share of households taking certain actions from the moment of purchasing chicken meat up until consumption or disposal is visualised in Figure 1.

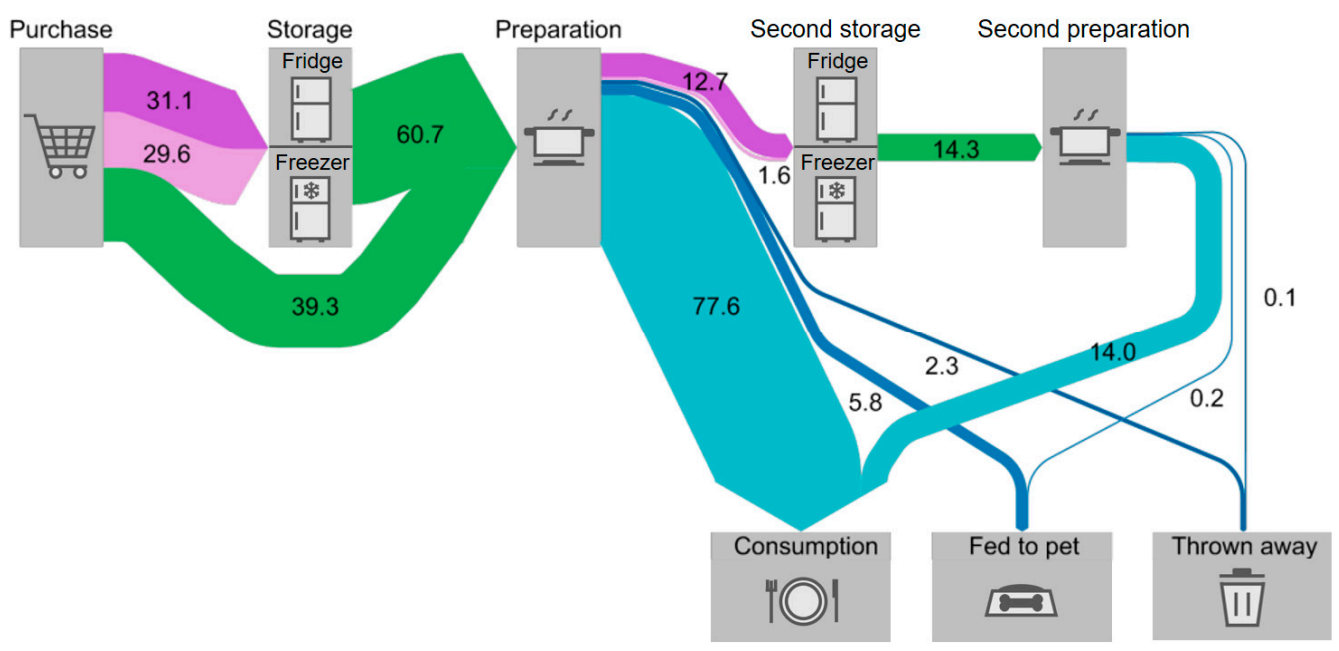

Figure 1. Actions taken after purchasing chicken meat, up to consumption and/or disposal, $\%$ of households $(n=256)$. When multiple actions were taken, equal weight was assumed.

Wastage of chicken meat only occurred after food preparation, both when the product was prepared for the first and the second time. After the first preparation, $8.1 \%$ of the households discarded a fraction of the meat, whereas $77.6 \%$ consumed the entire product and $14.3 \%$ stored the meal. Of this wasted portion, $5.8 \%$ of the households gave it to their pets and $2.3 \%$ dumped it as refuse. After the second preparation of the stored meal $(14.3 \%), 0.3 \%$ of the households reported its wasting, while $14.0 \%$ reported its consumption. Five times more households reported wasting after the first consumption than after the second consumption.

When chicken leftovers were thrown away, the main reasons were the fact that too much had been bought $(23.1 \%)$, the unpredictability of children $(23.1 \%)$ and inappropriate packaging size (too big or too small) (23.1\%) (see Figure 2). The unpredictability of children refers, for example, to the fact that children were less hungry than expected or that they, quite unexpectedly, did not have dinner at home. When chicken meat was fed to pets, the most important reasons were that households had bought too much $(36.4 \%)$ or had bought it intending to give it to their pet (33.3\%). Independent of the destination of the waste, households reported that $11 \%$ of chicken meat waste amounts was due solely to the size of the packaging (assuming the same mass per served portion). This is consistent with the study of [15], which found that $20-25 \%$ of food waste may be caused by food product determinants. These wastages were dominated by packaging size, difficulties with emptying and the fact that the 'best before date' had passed. Packaging size and emptying ability led to a food waste of only $5-16 \%$. In this paper, the degree of emptiability was not applicable because the chicken meat products could be easily removed from the packaging without leaving any parts inside. 


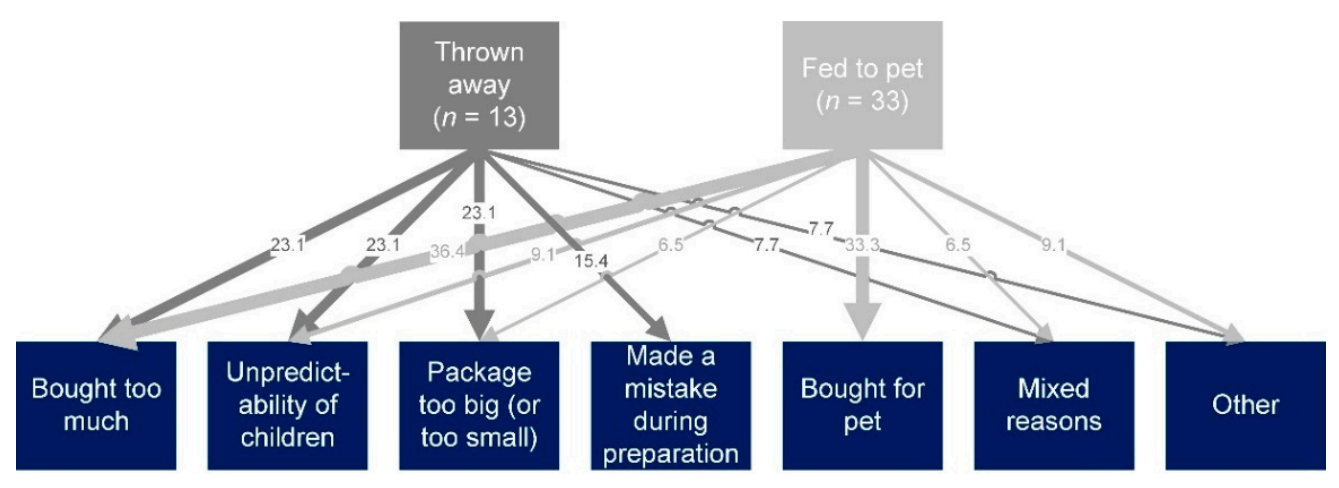

Figure 2. Reasons for household chicken waste, in percentages, in case the meat was fed to the households' pet or thrown away.

\subsection{Segmentation into Household Waster Segments}

Households were segmented based on their self-reported chicken meat waste percentages (Section 3.4) and are further called household waster segments (HWS). A first segment-of which the participants claimed never to waste any chicken-was separated from the remaining sample. The remaining households were divided into three segments. The reason to introduce three segments was two-fold: a sufficient number of segments were preferred and each segment needed to have a substantial size for statistical comparison in order to draw a meaningful conclusion.

Two options were investigated on how to classify the remaining households into these segments: a division with an equal number of households per segment and a division with the 25th and 75th percentile as thresholds. The threshold values for the first option were $0.0,1.0$, and $3.0 \%(w / w)$ of food wasted and $0.0,0.6$, and $5.0 \%$ of the second option. Both options seemed valuable because a similar trend was discovered related to significant differences between the segments (Supplementary Section S2).

These differences were based on reported household actions up to first consumption (partially Part 2), self-reported food waste (Part 3) and consumer determinants (Part 4). A similar number of responses differed statistically significantly between the two HWS options. In addition, one response on planning behaviour was statistically significantly different for the option with the 25th and 75th percentiles as thresholds. Cross tabulation analyses were tested for categorical variables and Kruskal-Wallis tests for Likert-scale variables and continuous variables. These significant results did not lead to a preference for one option over the other. Therefore, the option with an equal number of households per segment was selected to ensure a straightforward interpretation of the threshold values $(0.0,1.0$ and $3.0 \%)$.

The range and average percentage of chicken waste of the chosen HWS option can be found in Figure 3. The four HWS were called HWS 0\%, HWS ]0-1[\%, HWS [1-3]\%, and HWS $>3 \%$. This means-for example - that the unconsumed chicken percentage of households in HWS $] 0-1[\%$ is more than $0.0 \%$ and less than $1.0 \%$. The average percentages of chicken meat waste collected as part of the survey were lower than the FAO estimates for meat products in general across Europe and Russia (11\%). This FAO percentage is an estimate or assumption based on the FAO's Food Balance and additional research [1]. As mentioned in Section 2.4, different sampling methods may have been used in both this study and the FAO study. This discrepancy can lead to difficulties in comparing the results [39]. 


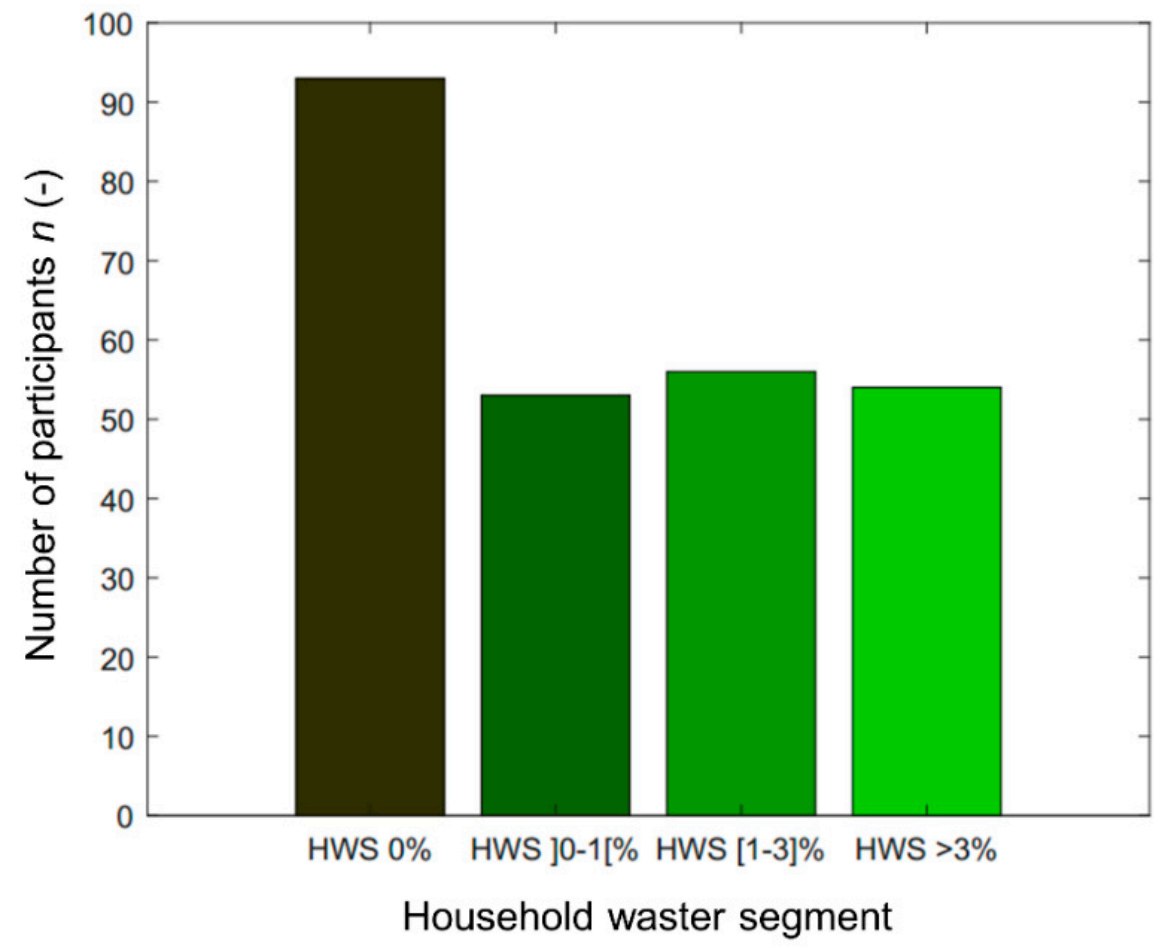

Chicken waste percentage:

\begin{tabular}{|c|c|c|c|c|}
\hline Range (\%) & 0.0 & ]0.0, 1.0[ & {$[1.0,3.0]$} & ] $3.0,24.8[$ \\
\hline Average (\%) & 0.0 & 0.4 & 1.8 & 8.3 \\
\hline
\end{tabular}

Figure 3. Household waster segments (HWS) and their participants including the range and average percentage of unconsumed chicken meat.

\subsection{Consumer Determinants}

Relation between Consumer Determinants and Household Waster Segments

In this section, the consumer determinants that are significantly different for some HWS are assessed. Seven sociodemographic characteristics, four household routines and skills and ten motivations and attitudes were analysed (Table 2). Ten consumer determinants varied significant amongst HWS, in particular, three sociodemographic characteristics, all four analysed household routines and skills and three motivations and attitudes. Additional information of the statistical results can be found in Supplementary Section S3. The results with the lowest $p$-values related to two sociodemographic characteristics, two household routines and skills, and two motivations and attitudes are presented in Figure 4.

Less chicken waste was generated in households consisting older participants $(p<0.001)$, with no children $(p=0.010)$, and / or with unemployed participants $(p=0.021)$. A higher share of HWS $0 \%$ was found with increasing age classes (Figure 4). Participants younger than 50 were overrepresented in the HWS $[1-3] \%$ and HWS $>3 \%$. Households without children had a high share within HWS $0 \%$ and a lower share in HWS [1-3] $\%$ and HWS 3\%. Additionally, determinants without a significant association with HWS were gender, children younger than 12 years old in the household, highest level of education, employment status and financial status.

Regarding sociodemographic characteristics, this investigation confirms the results from studies in which lower food waste levels are associated with older participants $[10,11]$ Similar to the present research, some studies reported no significant links between income and household waste levels [10], although others did establish a relationship [11]. The household composition showed-in contrast to the present paper-no correlation with household food levels in the research of [10]. 
A significant association was reported between the segments and all four investigated household routines and skills - namely, planning routines $(p=0.003)$, shopping routines $(p=0.008)$, leftover reuse routines $(p=0.012)$ and household skills $(p=0.012)$ (Table 2$)$. In general, the more that participants mentioned planning their shopping trips in advance (planning routines), the less chicken meat was wasted (Figure 4). An exception to this finding was HWS [1-3]\%. In particular, a significant difference could only be noted between HWS $>3 \%$ and both HWS $0 \%(p=0.009)$ and HWS [1-3] $\%(p=0.006)$. When more chicken meat was discarded, participants indicated that they buy more food products than intended (shopping routines). Significant differences related to shopping routines were reported between HWS $0 \%$ and HWS > 3\% $(p=0.015)$. In addition, lower levels of self-reported chicken waste were linked to participants who indicated better routines for reusing leftovers and better household skills. A significant difference was only visible for HWS $0 \%$ and HWS > 3\% for both determinants (respectively $p=0.008$ and $p=0.027$ ). Similar trends appeared in the literature related to shopping, leftover reuse, and planning routines [11].

Table 2. Statistical differences based on chi-square and Kruskal-Wallis tests (significance values adjusted by the Bonferroni correction) between various household waster segments (HWS) related to consumer determinants: sociodemographic characteristics, household routines and skills and motivations and attitudes.

\begin{tabular}{|c|c|}
\hline & $p$-Value \\
\hline \multicolumn{2}{|l|}{ Sociodemographic Characteristics } \\
\hline Age class $(18-32,33-50,51-59, \geq 60)$ & $<0.001$ \\
\hline Household composition (with children vs. without children) & 0.010 \\
\hline Employment status (employed vs. unemployed) & 0.021 \\
\hline Gender (male vs. female) & 0.225 \\
\hline Children younger than 12 yr. (yes vs. no) & 0.341 \\
\hline Highest educational level (education after 18 yr. vs. no education after 18 yr.) & 0.810 \\
\hline Financial status ((rather) difficult, neither easy nor difficult, (rather) easy) * & 0.899 \\
\hline \multicolumn{2}{|l|}{ Household Routines and Skills } \\
\hline $\begin{array}{c}\text { Planning routines-The shopping trips are usually planned in advance (shopping lists are made, inventories } \\
\text { are checked, etc.) }\end{array}$ & 0.002 \\
\hline Shopping routines-We often buy unintended food products when shopping & 0.007 \\
\hline Leftover reuse routines-The leftovers are stored in appropriate conditions so they will last longer & 0.010 \\
\hline $\begin{array}{l}\text { Household skills-Thinking about the activities related to food within your home, how would you rate your } \\
\text { household's skills, in terms of planning meals }\end{array}$ & 0.023 \\
\hline \multicolumn{2}{|l|}{ Motivations and Attitudes } \\
\hline Intention not to waste food-I try not to throw away food & $<0.001$ \\
\hline Injunctive norm-One should never waste food, not burden the environment with food waste & $<0.001$ \\
\hline Perceived consumer effectiveness-I believe that every small effort by consumers helps to reduce food waste & 0.012 \\
\hline $\begin{array}{l}\text { Self-evaluated ecological footprint-The ecological footprint is the estimated surface area that a person or group of } \\
\text { people needs to produce what is consumed and to absorb what is discarded. How would you estimate your own } \\
\text { ecological footprint? }\end{array}$ & 0.184 \\
\hline Compare chicken with vegetables-In comparison with vegetables & 0.077 \\
\hline I try to throw away less chicken & 0.776 \\
\hline I buy chicken less often unplanned & 0.867 \\
\hline I reuse chicken surpluses more often & 0.055 \\
\hline I plan the purchase of chicken more & 0.316 \\
\hline I think throwing away chicken is rather negative & 0.151 \\
\hline
\end{tabular}

Significant $p$-values $(<0.05)$ are indicated in bold. * Participants answering 'I do not want to tell' were excluded from this analysis $(n=6)$. 


\section{(a) Sociodemographic characteristics}

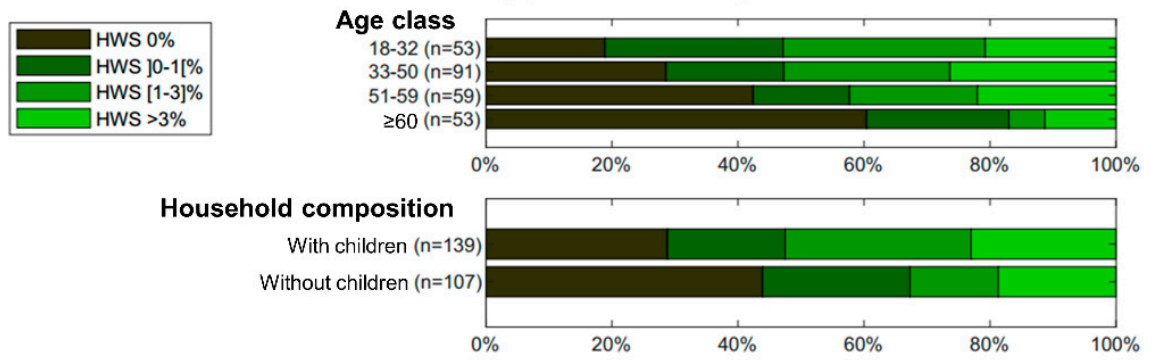

(b) Household routines and skills
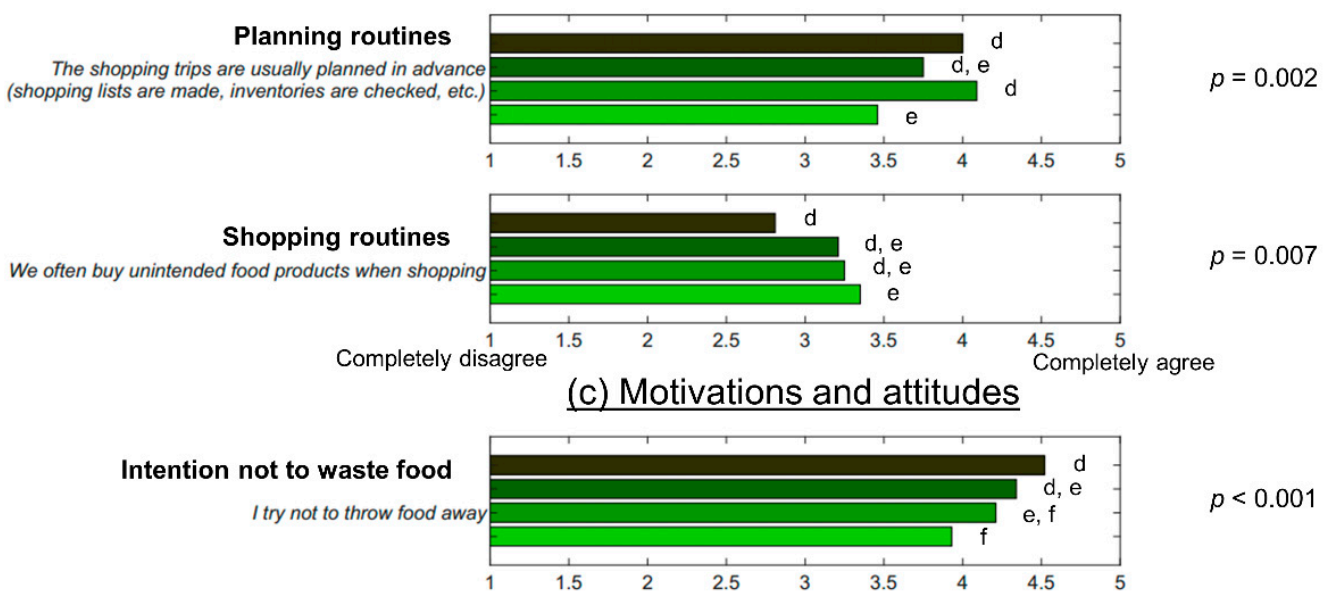

$p<0.001$

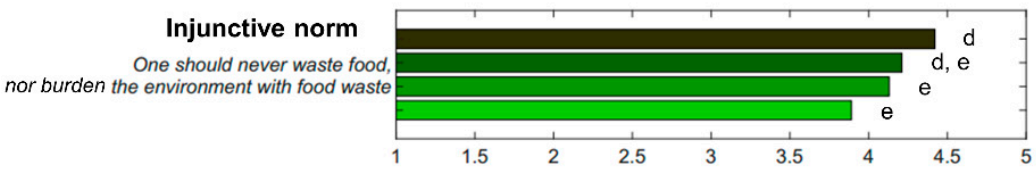

$p<0.001$

Completely disagree

Completely agree

Figure 4. The statistically significant ( $p$-value $<0.05)$ consumer determinants: (a) sociodemographic characteristics, (b) household routines and skills and (c) motivations and attitudes of the four household waster segments (HWS), HWS 0\% $(n=93)$, HWS ]0-1[\% $(n=53)$, HWS [1-3]\% $(n=56)$, and HWS $>3 \%(n=54)$. Scaling; $1=$ completely disagree, $2=$ disagree, $3=$ neutral, $4=$ agree, $5=$ completely agree. $(\mathbf{b}, \mathbf{c})$ are expressed as means; medians are often uniform and the distribution is not bimodal. $\mathrm{d}, \mathrm{e}, \mathrm{f}$ : mean values with different letters indicate significantly different means using $p<0.05$.

Some motivations and attitudes showed a significant association with HWS. Participants who indicated that they discard lower amounts of chicken meat reported higher levels of agreement with the intention not to waste food $(p<0.001)$, the injunctive norm $(p<0.001)$ and the perceived consumer effectiveness $(p=0.021)$. Similar to household routines and skills, significant differences did not appear systematically amongst all HWS. For the intention not to waste food, HWS $0 \%$ was significantly different from both HWS $[1-3] \%(p=0.024)$ and HWS $>3 \%(p<0.001)$ and HWS $] 0-1[\%$ from HWS $>3 \%(p=0.004)$ (Figure 4). Concerning the injunctive norm, HWS $0 \%$ was significantly different from HWS ]0-1[\% $(p=0.035)$ and HWS $>3 \%(p<0.001)$. Perceived consumer effectiveness was only significantly different between HWS $0 \%$ and HWS $>3 \%(p=0.044)$.

The observation on the injunctive norm is in line with [11] that showed a weak significant effect regarding this norm. In contrast, the results of the study of [12] indicated that the injunctive norm was not related to self-reported food waste levels. 


\subsection{Food Product Determinants}

\subsubsection{Waste Percentage of the Entire Sample}

In this section, the share of participants wasting and the self-reported waste percentages are described for all chicken products and the entire sample: participants claiming to never waste (non-wasters) and participants indicating waste (wasters). Overall, $36 \%$ of the participants declared never wasting any chicken meat (HWS $0 \%$ ). This percentage was higher for some chicken products: organic whole chicken $1.5 \mathrm{~kg}(60.0 \%)$ and chicken breasts $0.5 \mathrm{~kg}(42.2 \%)$ (Table 3). A relatively high share of wasters, or all segments, except HWS $0 \%$, was observed for diced chicken breast $0.5 \mathrm{~kg}(74.6 \%)$, chicken breast $1 \mathrm{~kg}(70.9 \%)$ and chicken escalope $0.4 \mathrm{~kg}(64.6 \%)$. The waste percentage of all households and wasters varied between products, although they were not significantly different. These percentages are, respectively, the average waste percentage of all households or only those participants who indicated to waste that frequently buy a specific chicken product. Chicken breast $1 \mathrm{~kg}$ had the highest waste share of all households (3.1\%) and organic whole chicken the lowest $(1.1 \%)$. Overall, the waste percentage of the wasters showed similar trends-again, without a significant difference. The waste percentage proclaimed the highest for chicken breasts $1 \mathrm{~kg}(4.4 \%)$ and the lowest for both diced chicken breast (2.6\%) and organic whole chicken $(2.8 \%)$. It is essential to highlight that the food waste percentages were obtained through self-reporting, as discussed in Section 4.2.

Table 3. Percentage of non-wasters (HWS 0\%), wasters (HWS ]0-1[\%, HWS [1-3]\%, and HWS > 3\% together), waste percentage of all households and waste percentage of the wasters per chicken product ( $p$-values quantified by chi-square test).

\begin{tabular}{|c|c|c|c|c|}
\hline & \multicolumn{2}{|c|}{ All Households } & \multirow{2}{*}{$\begin{array}{l}\text { Waste Percentage of } \\
\text { All Households (\%) }\end{array}$} & \multirow{2}{*}{$\begin{array}{c}\text { Waste Percentage } \\
\text { Wasters (\%) }\end{array}$} \\
\hline & Non-Wasters (\%) & Wasters (\%) & & \\
\hline Diced chicken breasts $0.5 \mathrm{~kg}(n=59)$ & 25.4 & 74.6 & 1.9 & 2.6 \\
\hline Chicken breasts 1 kg $(n=55)$ & 29.1 & 70.9 & 3.1 & 4.4 \\
\hline Chicken breasts $0.5 \mathrm{~kg}(n=64)$ & 42.2 & 57.8 & 2.2 & 3.8 \\
\hline Chicken escalope $0.4 \mathrm{~kg}(n=48)$ & 35.4 & 64.6 & 2.3 & 3.5 \\
\hline Organic whole chicken $1.5 \mathrm{~kg}(n=30)$ & 60.0 & 40.0 & 1.1 & 2.8 \\
\hline$p$-value & - & - & 0.261 & 0.451 \\
\hline
\end{tabular}

\subsubsection{Relation between Food Product Determinants and HWS}

All five observed determinants were significantly different between segments (Figure 5). Additional information of the statistical results can be found in Supplementary Section S4. A significant association was reported between the segments and the product itself $(p=0.019)$. Higher food waste percentages were shown in the case that the product was not organic $(p=0.011)$ and for both a higher convenience grade $(p=0.013)$ and a longer shelf life $(p=0.036)$. The packaging size was significantly different between segments $(p=0.019)$. Considering the product itself, households within HWS $0 \%$ had a higher share for organic whole chicken $1.5 \mathrm{~kg}$ and-to a smaller extent-for chicken breasts $0.5 \mathrm{~kg}$, compared to the remaining products. In addition, for organic whole chicken, the households in HWS [0-1]\% were represented to a lower extent than regarding the other chicken products. Participants purchasing diced chicken breasts were overrepresented in HWS [1-3]\%. Moreover, households within HWS $>3 \%$ had a high share of chicken breast $1 \mathrm{~kg}$ and a low share of organic whole chicken. Relating to the agricultural production system, households within HWS $0 \%$ were, to a greater extent, present in the group that purchased organic chicken products and households within HWS $] 0-1[\%$ and HWS $>3 \%$ to a smaller extent. When considering the food convenience grade, HWS $0 \%$ was overrepresented for the group purchasing nonconvenience foods, although HWS ]0-1[\% was underrepresented in this group. Related to the packaging size, similar trends of non-convenience foods were found for households purchasing large packaging sizes. Moreover, when only medium and small packaging sizes were compared, small packages resulted in smaller amounts of chicken waste. Within the group of households buying small packages, HWS $>3 \%$ was underrepresented and 
HWS $0 \%$ together with HWS [1-3]\% was overrepresented. For products with a limited shelf life, households belonging to HWS $0 \%$ had a high share, whereas households from the remaining segments had a low share.

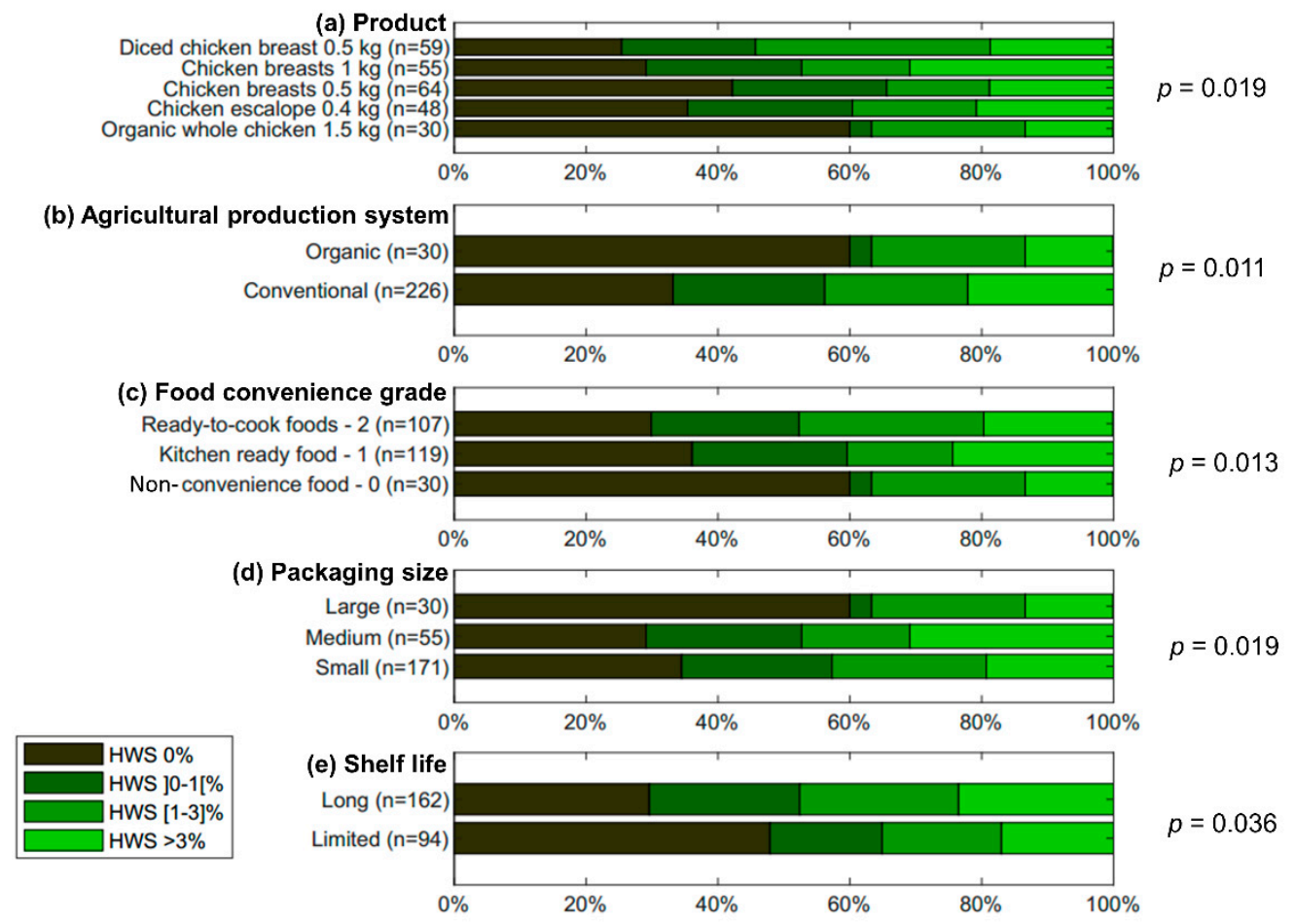

Figure 5. Food product determinants-(a) product, (b) agricultural production system, (c) food convenience grade, (d) packaging size and (e) shelf life-for the four household waster segments (HWS): HWS 0\% $(n=93)$, HWS ]0-1[\% $(n=53)$, HWS [1-3] $\%(\mathrm{n}=56)$, and HWS > 3\% $(n=54)$. $p$-values quantified by chi-square test.

The present study suggests that households buying organic food products waste less chicken meat, possible because it is bought more expensively and/or reducing waste is consistent with the philosophy of consumers that frequently buy organic food. However, there was no report of an association between eating organic foods and decreasing amounts of food waste [37]. Products with a higher food convenience grade are more wastedpossibly because portion-size is predetermined and not appropriate to the individual consumer's needs, because the product does not entirely match with expectations (e.g., in terms of taste) or because the product is less versatile for other consumption occasions or less suitable for storage as left-overs. In contrast to the present results, a higher food convenience grade was perceived as a measure to reduce food waste [38]. The observation that a longer shelf life leads to more chicken waste is contrary to the study of Zhang et al. (2019). However, no direct relationship was reported between longer shelf life and the occurrence of food waste generation [36]. In conclusion, some findings in the present study are in contrast with the reviewed literature with some food product determinants influencing food waste to a greater extent (e.g., whether households buy organic products) than others (e.g., shelf life of products). For example, similar to the study of [11] focusing on the variance of household food waste observed by consumer determinants, some food product determinants may explain the variance of food waste levels more than others.

Attention should be paid to the order of questions in the survey, as it could prime the participants [45]. This can result in unconsciously altering their answers, for example underreporting food waste levels. Moreover, for some food product determinants, the number of participants per group was not always balanced. For example, the groups of different agricultural production systems were $n=30$ for organic and $n=226$ for conventional. 


\section{Conclusions}

Wastage of food is a global environmental concern, in particular with respect to the role of households to which half of the environmental impact associated with food waste can be attributed [2]. The issue of discarding food is shaped by consumer and food product determinants. Research focusing on both determinants to evaluate household food wastage is largely lacking in the domain of packed food products. Therefore, this study assessed the relationship between both consumer and food product determinants and the wastage of chicken meat by households. Overall, $36 \%$ of the participants declared never wasting any chicken meat. The average waste percentages were small and ranged from 1.1 to $3.1 \%$, depending on the packaged product, although the percentages were not significantly different between the products. When wasted, the main reasons were due to buying too much, the unpredictability of children and inappropriate packaging sizes. In cases where chicken meat leftovers were fed to pets, the most important justification was that households had either bought too much or had bought it with the intention of giving it to their pet. Next, households were segmented based on their self-reported chicken meat waste. Four HWS were identified, called HWS 0\%, HWS ]0,1[\%, HWS $[1-3] \%$ and HWS $>3 \%$. The present analyses demonstrated that households with lower rates of self-reported chicken waste were characterised by participants of older age, no presence of children and/or unemployed participants. Moreover, lower waste households scored significantly stricter for some household routines and skills, namely shopping routines, leftover reuse routines and household skills. The households with a lower level of chicken waste agreed to a significantly greater extent with the intention not to waste food, the injunctive norm and perceived consumer effectiveness. Looking at food product determinants, less waste was reported by households that purchased organic chicken meat and by households that bought products with both a lower convenience grade and shorter shelf life. In conclusion, some of the present research findings are in contrast with the current literature, as some food product determinants influenced food waste to a higher extent (e.g., if households buy organic products) than others (e.g., shelf life of products). The results of this study suggest possibilities for future research. Firstly, the effects of both consumer and food product determinants on food waste generation in households is recommended to be included in environmental studies, consumer household actions in particular. Secondly, additional consumer studies on other packaged fresh products (such as cheese and vegetables) can be performed to assess packaging-related FLW across a broader range of food products. Thirdly, the self-reported percentage of household food waste may be underestimated, e.g., as a result of social desirability bias. Similar research can be executed, using objective measurements based on physical waste surveys to benchmark results from this study. Fourthly, a rule of thumb was used to define the number of participants per segments $(n=30)$. The results of this study, and in particular the between and within segment variances, can be used in future research to perform formal power analyses, thereby obtaining a data-driven estimate for the required number of cases in each of the segments, and the total number of cases in the study.

In particular, to take these results a step further, the environmental consequences of consumer and food product determinants on food wastage should be investigated. This future research is highly recommended, as half of the overall climate impact of FLW along the food supply chain can be attributed to households [2]. Integration of packagingrelated FLW in studies assessing the environmental impact (e.g., by LCA) of packaging is also essential to gain a more complete picture of the overall product environmental burden [30]. It is particularly recommended to assess the impact based on consumption of a product instead of its production. The authors of [46] performed an environmental assessment by including packaging-related FLW as a result of the poor emptiability of tomato ketchup. Focusing on additional food product determinants, such as packaging size, is, therefore, advisable. 
Supplementary Materials: The following are available online at https://www.mdpi.com/article/10 $.3390 /$ su13137027/s1, Table S1: Segment names and the number of participants per segment of the two household waster segment (HWS) options, Table S2: p-values of the cross tabulation analysis of the two HWS options: a division with an equal number of participants per segment or a division with the 25th and 75th percentile as thresholds, Table S3: Sociodemographic characteristics of the complete sample $(n=256)$, Table S4: Sociodemographic characteristics: differences between household waster segments (HWS), Table S5. Household routines and skills: differences between household waster segments (HWS), Table S6: Motivations and attitudes: differences between household waster segments (HWS), Table S7: Food product determinants: differences between household waster segments (HWS). References used in the Supplementary: [11,15,31].

Author Contributions: Conceptualisation, M.C.-A., F.M., L.B., S.E.T. and J.D.; data curation, M.C.-A., F.M. and K.B.; formal analysis, M.C.-A., F.M., K.B., W.V., B.D. and Y.H.; investigation, M.C.-A., F.M. and K.B.; methodology, M.C.-A., F.M., K.B., Y.H. and B.D; project administration, M.C.-A.; supervision, J.D.; visualisation, M.C.-A.; writing-original draft, M.C.-A.; writing-review and editing, M.C.-A., F.M., L.B., S.E.T., W.V., B.D. and J.D. All authors have read and agreed to the published version of the manuscript.

Funding: This research received no external funding.

Institutional Review Board Statement: All subjects gave their informed consent for inclusion before they participated in the study. The study was conducted in accordance with the Declaration of Helsinki, and the protocol was approved by the Ethics Committee of the Faculty Psychology and Educational Sciences, Ghent University, Belgium (2019/68/Margot Cooreman-Algoed, 15 October 2019).

Informed Consent Statement: Informed consent was obtained from all subjects involved in the study.

Data Availability Statement: Restrictions apply to the availability of these data. Data were obtained from Colruyt Group and are not publically available.

Acknowledgments: The authors wish to thank the Colruyt Group colleagues for their input into the case study and for enabling the consumer survey at the Colruyt and Bio-Planet shops. We are grateful to colleagues from our research group STEN (Ghent University) for testing the consumer survey. We express our gratitude to the survey participants for their collaboration in the study. Nelly De Rouck was consulted for language-related feedback.

Conflicts of Interest: The authors declare no conflict of interest.

\section{References}

1. FAO. Global Food Losses and Food Waste-Extent, Causes and Prevention; Food and Agriculture Organization of the United Nations (FAO): Rome, Italy, 2011.

2. Beretta, C.; Stucki, M.; Hellweg, S. Environmental impacts and hotspots of food losses: Value chain analysis of swiss food consumption. Environ. Sci. Technol. 2017, 51, 11165-11173. [CrossRef]

3. WRAP. Household Food and Drink Waste in the UK; Waste and Resources Action Programme (WRAP): Banbury, UK, 2009.

4. Huysman, S.; Schaubroeck, T.; Goralczyk, M.; Schmidt, J.; Dewulf, J. Quantifying the environmental impacts of a european citizen through a macro-economic approach, a focus on climate change and resource consumption. J. Clean. Prod. 2016, 124, 217-225. [CrossRef]

5. Heller, M.C.; Keoleian, G.A. Greenhouse gas emission estimates of U.S. Dietary choices and food loss. J. Ind. Ecol. 2015, 19, 391-401. [CrossRef]

6. UN. Transforming Our World: The 2030 Agenda for Sustainable Development; United Nations (UN): New York, NY, USA, 2015.

7. FAO. The State of Food and Agriculture 2019. Moving Forward on Food Loss and Waste Reduction; Food and Agriculture Organization of the United Nations (FAO): Rome, Italy, 2019.

8. Chaboud, G.; Daviron, B. Food losses and waste: Navigating the inconsistencies. Glob. Food Secur. 2017, 12, 1-7. [CrossRef]

9. Delgado, L.; Schuster, M.; Torero, M. Quantity and quality food losses across the value chain: A comparative analysis. Food Policy 2020, 98, 101958. [CrossRef]

10. van Geffen, L.; van Herpen, E.; van Trijp, H. Quantified Consumer Insights on Food Waste-Pan-European Research for Quantified Consumer Food Waste Understanding; Wageningen UR: Wageningen, The Netherlands, 2017.

11. Stancu, V.; Haugaard, P.; Lahteenmaki, L. Determinants of consumer food waste behaviour: Two routes to food waste. Appetite 2016, 96, 7-17. [CrossRef]

12. Stefan, V.; van Herpen, E.; Tudoran, A.A.; Lähteenmäki, L. Avoiding food waste by romanian consumers: The importance of planning and shopping routines. Food Qual. Prefer. 2013, 28, 375-381. [CrossRef] 
13. Visschers, V.H.M.; Wickli, N.; Siegrist, M. Sorting out food waste behaviour: A survey on the motivators and barriers of self-reported amounts of food waste in households. J. Environ. Psychol. 2016, 45, 66-78. [CrossRef]

14. Principato, L.; Secondi, L.; Pratesi, C.A. Reducing food waste: An investigation on the behaviour of italian youths. Br. Food J. 2015, 117, 731-748. [CrossRef]

15. Williams, H.; Wikström, F.; Otterbring, T.; Löfgren, M.; Gustafsson, A. Reasons for household food waste with special attention to packaging. J. Clean. Prod. 2012, 24, 141-148. [CrossRef]

16. Lindh, H.; Williams, H.; Olsson, A.; Wikström, F. Elucidating the indirect contributions of packaging to sustainable development: A terminology of packaging functions and features. Packag. Technol. Sci. 2016, 29, 225-246. [CrossRef]

17. Robertson, G. Food Packaging and Shelf Life: A Practical Guide; Taylor \& Francis Inc.: Boca Raton, FL, USA, 2009.

18. FAO. Available online: http:/ / www.fao.org/faostat/en/\#data/FBS (accessed on 12 December 2020).

19. Clune, S.; Crossin, E.; Verghese, K. Systematic review of greenhouse gas emissions for different fresh food categories. J. Clean. Prod. 2017, 140, 766-783. [CrossRef]

20. Yavas, E.; Bilgin, B. Effect of calcium lactate, sodium diacetate and sodium chloride mixture on the microbiological, chemical and sensory properties of chicken nuggets stored in refrigeration and under modified atmospheres. Int. J. Poult. Sci. 2010, 9, 66-71. [CrossRef]

21. WHO. The Global View of Campylobacteriosis Report of Expert Consultation; World Health Organization (WHO): Utrecht, The Netherlands, 2012.

22. Strachan, N.J.; Rotariu, O.; MacRae, M.; Sheppard, S.K.; Smith-Palmer, A.; Cowden, J.; Maiden, M.C.; Forbes, K.J. Operationalising factors that explain the emergence of infectious diseases: A case study of the human campylobacteriosis epidemic. PLoS ONE 2013, 8, e79331. [CrossRef] [PubMed]

23. Baltic, T.; Ciric, J.; Brankovic Lazic, I.; Ljubojevic Pelic, D.; Mitrovic, R.; Djordjevic, V.; Parunovic, N. Packaging as a tool to improve the shelf life of poultry meat. IOP Conf. Ser. Earth Environ. Sci. 2019, 333, 012044. [CrossRef]

24. Bravi, L.; Francioni, B.; Murmura, F.; Savelli, E. Factors affecting household food waste among young consumers and actions to prevent it. A comparison among uk, spain and italy. Resour. Conserv. Recycl. 2020, 153, 104586. [CrossRef]

25. Di Talia, E.; Simeone, M.; Scarpato, D. Consumer behaviour types in household food waste. J. Clean. Prod. 2019, $214,166-172$. [CrossRef]

26. Schwodt, S.; Obersteiner, G. Development of tailor-made food waste prevention measures based on consumer type analysis. Sci. Pap.-Ser. A-Agron. 2018, 61, 513-515.

27. Gaiani, S.; Caldeira, S.; Adorno, V.; Segre, A.; Vittuari, M. Food wasters: Profiling consumers' attitude to waste food in italy. Waste Manag 2018, 72, 17-24. [CrossRef] [PubMed]

28. Funk, A.; Sütterlin, B.; Siegrist, M. Consumer segmentation based on stated environmentally-friendly behavior in the food domain. Sustain. Prod. Consum. 2021, 25, 173-186. [CrossRef]

29. Mirzaie-Nodoushan, F.; Morid, S.; Dehghanisanij, H. Reducing water footprints through healthy and reasonable changes in diet and imported products. Sustain. Prod. Consum. 2020, 23, 30-41. [CrossRef]

30. Wohner, B.; Pauer, E.; Heinrich, V.; Tacker, M. Packaging-related food losses and waste: An overview of drivers and issues. Sustainability 2019, 11, 264. [CrossRef]

31. Goossens, Y.; Schmidt, T.G.; Kuntscher, M. Evaluation of food waste prevention measures-The use of fish products in the food service sector. Sustainability 2020, 12, 6613. [CrossRef]

32. Gustavo, J.U.; Pereira, G.M.; Bond, A.J.; Viegas, C.V.; Borchardt, M. Drivers, opportunities and barriers for a retailer in the pursuit of more sustainable packaging redesign. J. Clean. Prod. 2018, 187, 18-28. [CrossRef]

33. Lanfranchi, M.; Calabro, G.; De Pascale, A.; Fazio, A.; Giannetto, C. Household food waste and eating behavior: Empirical survey. Br. Food J. 2016, 118, 3059-3072. [CrossRef]

34. Kirtil, E.; Kilercioglu, M.; Oztop, M.H. Modified atmosphere packaging of foods. Ref. Modul. Food Sci. 2016, 1, 1-6.

35. Zhang, B.Y.; Tong, Y.; Singh, S.; Cai, H.; Huang, J.-Y. Assessment of carbon footprint of nano-packaging considering potential food waste reduction due to shelf life extension. Resour. Conserv. Recycl. 2019, 149, 322-331. [CrossRef]

36. Dilkes-Hoffman, L.S.; Lane, J.L.; Grant, T.; Pratt, S.; Lant, P.A.; Laycock, B. Environmental impact of biodegradable food packaging when considering food waste. J. Clean. Prod. 2018, 180, 325-334. [CrossRef]

37. McCarthy, B.; Liu, H.B. Food waste and the 'green' consumer. Australas. Mark. J. 2017, 25, 126-132. [CrossRef]

38. Heard, B.R.; Bandekar, M.; Vassa, B.; Miller, S.A. Comparison of life cycle environmental impacts from meal kits and grocery store meals. Resour. Conserv. Recycl. 2019, 147, 189-200. [CrossRef]

39. Elimelech, E.; Ert, E.; Ayalon, O. Bridging the gap between self-assessments and measured household food waste: A hybrid valuation approach. Waste Manag 2019, 95, 259-270. [CrossRef]

40. Withanage, S.V.; Dias, G.M.; Habib, K. Review of household food waste quantification methods: Focus on composition analysis. J. Clean. Prod. 2021, 279, 123722. [CrossRef]

41. Giordano, C.; Alboni, F.; Falasconi, L. Quantities, determinants, and awareness of households' food waste in italy: A comparison between diary and questionnaires quantities'. Sustainability 2019, 11, 3381. [CrossRef]

42. Østergaard, S.; Hanssen, O.J. Wasting of fresh-packed bread by consumers-influence of shopping behavior, storing, handling, and consumer preferences. Sustainability 2018, 10, 2251. [CrossRef] 
43. Cardinaels, J. Colruyt Pikt Klanten Weg Bij de Concurrentie. Available online: https:/ /www.tijd.be/ondernemen/retail/colruytpikt-klanten-weg-bij-concurrentie/10137692.html (accessed on 12 March 2021).

44. ifu Hamburg. E!Sankey-Show the Flow. Available online: https://www.ifu.com/en/e-sankey/sankey-diagram/?gclid= Cj0KCQiAv6yCBhCLARIsABqJTjZ9nd26HzeJCC-zuqDAX0zgsW4C0k_UmHUF6YX_fCinZSChDNYu_psaAjz2EALw_wcB (accessed on 12 March 2021).

45. Hanley, C.; Duncan, M.J.; Mummery, W.K. The effect of changes to question order on the prevalence of 'sufficient' physical activity in an australian population survey. J. Phys. Act. Health 2013, 10, 390-396. [CrossRef]

46. Wohner, B.; Gabriel, V.H.; Krenn, B.; Krauter, V.; Tacker, M. Environmental and economic assessment of food-packaging systems with a focus on food waste. Case study on tomato ketchup. Sci. Total Environ. 2020, 738, 139846. [CrossRef] 